\title{
IDŐJÁRÁS
}

Quarterly Journal of the Hungarian Meteorological Service

Vol. 123, No. 4, October-December, 2019, pp. 409-433

\section{Validation of RegCM regional and HadGEM global climate models using mean and extreme climatic variables}

\author{
Ildikó Pieczka ${ }^{1, *}$, Judit Bartholy ${ }^{1,2}$, Rita Pongrácz ${ }^{1,2}$, and \\ Karolina Szabóné André ${ }^{1}$ \\ ${ }^{1}$ Department of Meteorology, Eötvös Loránd University \\ Pázmány P. s. 1/A, H-1117, Budapest, Hungary \\ ${ }^{2}$ Eötvös Loránd University, Faculty of Science, \\ Excellence Center, \\ Brunszvik u. 2, H-2462, Martonvásár, Hungary \\ *Corresponding Author E-mail: pieczka@nimbus.elte.hu
}

(Manuscript received in final form October 2, 2018)

\begin{abstract}
The horizontal resolution of global climate models (GCMs) is still too coarse to evaluate regional climatic differences, therefore, to analyze regional environmental changes, it is essential to downscale the GCM simulation results. One of the methods widely and most often used for this purpose is dynamical downscaling. In the present paper we examine the ability of a specific global (HadGEM2-ES) and a specific regional climate model (RegCM) to describe present climatic conditions in different geographical areas within the Med-CORDEX domain. Our main goal with this validation is to inform researchers, who are planning to complete climate change impact studies about the major characteristics of the simulation outputs, serving as important input in such studies. So we analyzed annual and seasonal mean fields, mean error fields relative to the reference measurements, and selected climate indices. On the basis of the results, dynamical downscaling generally cools the HadGEM results, which depends on the distance from the ocean, and orography. A clear improvement can be recognized in the root-meansquare error (RMSE) of temperature indices when using finer resolution. Moreover, dynamical downscaling with higher resolution often increases the precipitation in mountains. Furthermore, in order to quantify the potential added value of RegCM simulations, a complex measure was introduced to take into account both the magnitude and spatial extent of bias. The analysis shows a general improvement in the cold-related indices in Central Europe and all temperature-related climate indices in Western Europe. The influence of model resolution is usually so strong, that it results in the underestimation of precipitation indices changing into overestimation and vice versa.
\end{abstract}

Key-words: climate model, validation, added value, RegCM, HadGEM2-ES, extreme indices, Europe, Hungary 


\section{Introduction}

Although the resolution of climate models is continuously improving as computational capacity increases, the differences between the outputs of global climate models (GCMs) and regional climate models (RCMs) are still clearly visible. It is important to note that these differences are not exclusively due to their different resolutions (Di Luca et al., 2015; Flaounas et al., 2013; Torma et al., 2015). Besides the evident spatial difference, another important factor is the different ultimate goals of their uses: global models are designed to simulate large-scale processes (e.g., midlatitude cyclones, anticyclones), whereas regional models should provide more details related to smaller scale phenomena (as the use of finer grids allows explicit representation of small-scale processes, e.g., mesoscale circulations, specific hydrodynamic instabilities, surface-forced processes, and the rain-shadow effect of mountains). To study regional scale changes, it is essential to downscale the GCMs, even if this might introduce additional uncertainties into the system of physical modeling through the final selection of the methods, models, parameterizations used. Either statistical or dynamical approaches, or their combination, can be used to downscale the GCM results (Maraun et al., 2015), and in this paper we apply dynamical downscaling (Giorgi, 1990).

A general improvement of model performance can be seen through the consecutive generation of climate models (from their initial versions to the most recent developments), which is partly due to (i) the generally higher horizontal resolution that up-to-date computing capacities allow, and (ii) the associated improvement of the representation of meteorological processes in the models. Among the numerous possible measures of model quality, the most often used measure is the simple bias, when several models are considered then the difference between the multi-model mean and a reference provides an overall quick evaluation of the set of models. The multi-model mean of the annual mean temperature of the CMIP5 (Coupled Model Intercomparison Project Phase 5, which compares global coupled ocean-atmosphere general circulation models, cmip.llnl.gov) historical experiments (i.e., using the observed records of atmospheric composition including the anthropogenic influences, and the time series of solar and volcanic forcings as boundary conditions) in the MedCORDEX area (for the 1980-2005 period) agrees well with the reanalysis (typically within $1{ }^{\circ} \mathrm{C}$, while inconsistency within reanalysis datasets is below $0.5^{\circ} \mathrm{C}$, see Fig. 9.2 in IPCC, 2013). The bias of the seasonal cycle amplitude is relatively small for Central Europe, but has a southwest-northeast gradient as larger biases correspond to the areas of large seasonal amplitude (Fig. 9.3 in $I P C C$, 2013). Models tend to dry out the soil too effectively at high temperatures, which results in a generally enhanced warm bias in the warmer months in the cases of RCMs, and in the majority of CMIP3 and CMIP5 model simulations (- in IPCC, 2013). The problem may be related to the broadly used 
soil data in climate models as suggested by Anders and Rockel (2009). The simulation of large-scale patterns of precipitation has somewhat improved since the CMIP3 ensemble (e.g., Fig. 9.6 in IPCC, 2013; Joetzjer et al., 2013; Knutti et al., 2013). However, at regional scales, precipitation is still not simulated in CMIP5 as well as it is in RCMs, because the regional scale precipitation strongly depends on various local parameters. These are represented much better in RCMs than in GCMs (i.e., finer topography, better land use/land cover representation, and more precise convection parameterization are available in RCMs). Nevertheless, the well-known large-scale features are reproduced well by the multi-model mean of GCM simulations. Considering extreme climatic conditions, both temperature and precipitation extremes (e.g., 20-year return values) are simulated relatively well by the CMIP3 and CMIP5 models. Moreover, none of the major climate quantities (e.g., sea ice extent, carbon sink, temperature at different atmospheric levels, etc.) show degradation from CMIP3 to CMIP5. Besides GCM development, the capability of RCMs to describe the past and present climatic conditions in Europe, and their potential added value compared to the global models is extensively studied. There is definitely high confidence that downscaling adds value when considering small-scale phenomena, extreme events, or complex topography (IPCC, 2013). Examples include the improved simulation of large-scale precipitation patterns for East Asia (Gao et al., 2012), convective precipitation (Rauscher et al., 2010), nearsurface temperature (Feser, 2006) and wind (Kanamaru and Kanamitsu, 2007), precipitation (Lucas-Picher et al., 2012), coastal climate features (Winterfeldt and Weisse, 2009; Winterfeldt et al., 2011; Kawazoe and Gutowski, 2013; Vautard et al., 2013), storms (Donat et al., 2010), midlatitude cyclones (Cavicchia and Storch, 2011), cutoff cyclones (Grose et al., 2012) and polar lows (Zahn and von Storch, 2008), or higher statistical moments of the water budget (Bresson and Laprise, 2011). RCMs can also improve the large-scale circulation with respect to that inherent in the boundary conditions (Veljovic et al., 2010).

Due to the large amount of generated data, researchers make choices when presenting their work: papers usually focus on specific features (e.g., on cyclogenesis in the Mediterranean by Flaounas et al., 2013) or sub-regions (e.g., the Alps in Torma et al., 2015). Another usual approach is to study several larger regions via an ensemble of numerous individual simulations (e.g., Giorgi et al., 2012; Coppola et al., 2014). In this case the diverse characteristics of the simulation results for different smaller subregions within the larger regions are only roughly described.

In this paper we compare and analyze a GCM simulation and a GCMdriven RCM run covering the Med-CORDEX area (defined in Somot et al., 2012), and validate their outputs focusing on European sub-regions for present climatic conditions. The representation of topography in the models over the 
area of interest (in the case of the regional model, after removing the buffer zone from the integration domain) can be seen in Fig. 1. For detailed regional scale analysis, four subregions are defined within the Med-CORDEX domain: Western, Eastern, Southern, and Central Europe, as seen in Fig. 1. They represent regions with different climate characteristics due to their geographical locations and orographical features (i.e., oceanic, continental, Mediterranean climate, and their 'mixture', respectively). To provide a general picture, first mean temperature and precipitation outputs are validated, and then we continue with an analysis of climate indices.
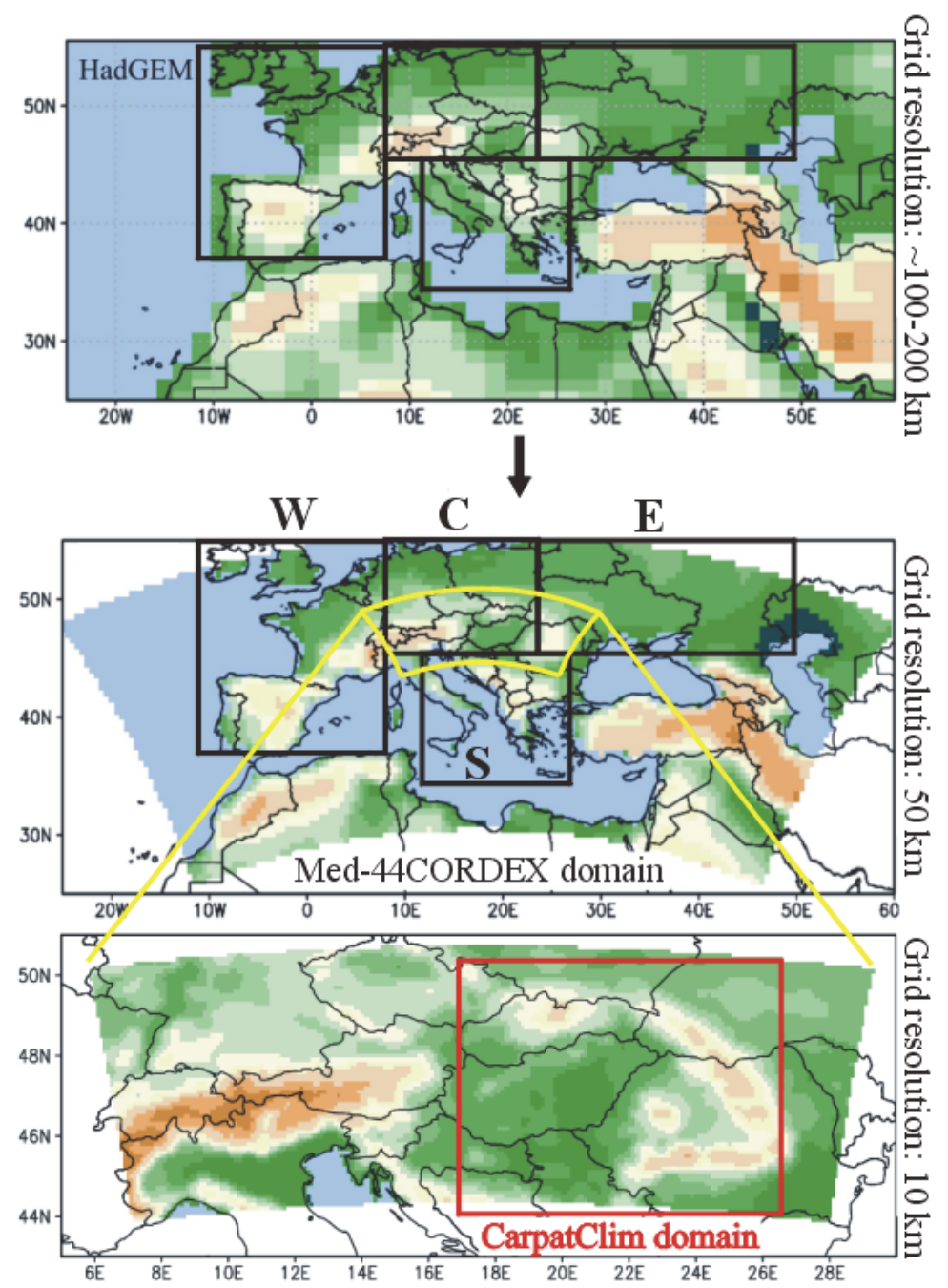

Height above sea level (m)

Fig. 1. Topography of the models for the domain of interest: HadGEM2-ES (top); RegCM4.3 with $50 \mathrm{~km}$ resolution (RegCM4.3_BATS_50km), Med-CORDEX domain (middle); RegCM4.3 with $10 \mathrm{~km}$ resolution (RegCM4.3 BATS 10km), Central European domain (bottom). The black rectangles represent the selected areas (Western, Central, Eastern and Southern Europe), the yellow polygon and the red rectangle represent the domain for the nested run, and the Carpatclim domain, respectively. 
Afterwards, we proceed with a focus on our region of interest: we compare model outputs of a double-nested $10 \mathrm{~km}$ resolution simulation to the fine resolution Carpatclim database for Hungarian gridpoints, and we discuss the influence of resolution on the outputs across a chain of model simulations. The ultimate goal of the paper is to describe the weaknesses and strengths of our model simulation (performed for the past), and which may become one of the four candidate RCMs (Krüzselyi et al., 2011), which were adapted and run in Hungary, when completing future national impact studies. The experiments completed with a newer version of the RegCM serve as the input of such impact studies (e.g., in hydrological studies as presented in Kis et al., 2017). Both historical and scenario runs are available online (http://nater.mfgi.hu/en) for such studies in the framework of the NAGIS (National Adaptation Geographical Information System). Thus, the target audience of the paper includes researchers focusing on various climate change impacts, e.g., hydrological consequences, agricultural modeling, forestry, ecology, urban planning, etc. For such a wide range of users, the present open access journal is an ideal source of information at the start of their studies.

\section{Data and methods}

Our simulation was carried out using RegCM4, a limited-area, hydrostatic, compressible, sigma-p vertical coordinate model maintained at the ICTP (International Centre for Theoretical Physics), Trieste (Elguindi et al., 2011). According to the user guide (Elguindi et al., 2011), RegCM can use initial and lateral boundary conditions (ICBCs) from the following CMIP5 models: HadGEM, MPI, GFDL, Canadian model, EC-Earth, IPSL, EH5OM. We selected just one of these GCMs due to time and storage constraints. The entire experiment covered the period 1950-2005 with ICBCs from the HadGEM2-ES (Hadley Centre Global Environment Model version 2, Earth-System configuration, Collins et al., 2011) GCM, taking historical forcings (Jones et al., 2011) into account (i.e., using the historical record of greenhouse gases, aerosols, solar and volcanic changes).

Elguindi et al. (2014) found that HadGEM2-ES is characterized by a relatively good level of performance among CMIP5 models for most regions (including the Mediterranean region), which makes it a good choice for use as a driving GCM in our study. Moreover, it is a relatively high sensitivity model compared to the others, which is its advantage in use in climate change studies. This advantage is more obvious when using this climate model for estimating future climate conditions. However, since climate change studies require a reference period from the past with the same model setup, models sensitive to anthropogenic radiation forcing due to greenhouse gas concentration increase should be analyzed for the historical runs. 
The atmospheric component of HadGEM2-ES uses a horizontal latitude and longitude resolution of $1.25^{\circ} \times 1.875^{\circ}$ with 38 vertical levels (Collins et al., 2011). The oceanic component has a resolution of $1^{\circ}$ (increasing to $1 / 3^{\circ}$ at the equator) and 40 vertical levels (Collins et al., 2011). HadGEM2-ES represents interactive land and ocean carbon cycles and dynamic vegetation, moreover, it employs an interactive tropospheric chemistry scheme (Jones et al., 2011). The model timestep is $30 \mathrm{~min}$ (in case of the atmosphere and land components) and 1 $h$ (in case of the ocean component).

Our region of interest is the Med-CORDEX domain (more specifically, the Carpathian Basin), which is the smallest among all the CORDEX domains. Here, we analyze the extent to which the RegCM is able to refine the results of the HadGEM2-ES, and the differences between the simulations using different resolutions.

\subsection{Description of the RegCM settings}

The default Med-CORDEX project settings were used at $50 \mathrm{~km}$ horizontal resolution (Somot et al., 2012), which were provided by the ICTP, and the participants agreed to change only one parameter or method at a time. Our contribution to Med-CORDEX was to use RegCM with the activation of the subgrid BATS scheme (Biosphere-atmosphere Transfer Scheme), hereinafter referred to as RegCM4.3 BATS 50km. This means that the land surface processes are modeled by BATS version 1e (Dickinson et al., 1993) with the treatment for subgrid variability of topography, and land cover is determined using a mosaic-type approach (Giorgi et al., 2003). Each grid cell is divided into 25 subgrid cells, which results in a $10 \mathrm{~km} \times 10 \mathrm{~km}$ land surface grid cell for intermediate calculations. This is thought to improve the model performance while keeping the computational time shorter than that required for a finer resolution model run, since only surface physics is calculated on the fine grid, but the calculations of atmospheric processes keep the coarser, original grid.

Comparing the outputs of the RegCM4.3_BATS_50km simulation to the default ICTP simulation (which does not activate the subgrid BATS scheme), the difference can be considered relatively small, mostly below $1{ }^{\circ} \mathrm{C}$ for temperature, and $15 \mathrm{~mm} /$ month for precipitation. However, the activation of the scheme results in slight differences, which depend on the season. In general, our simulation is a little warmer than that of the ICTP's (downloaded from https://www.medcordex.eu/ Coppola et al., 2014), except in summer, when the Apennine Peninsula and the eastern regions appear to be somewhat colder. Furthermore, the precipitation difference between the two simulations on the Apennine Peninsula in summer increases to $15-30 \mathrm{~mm} / \mathrm{month}$, so our model run with the activated subgrid BATS scheme produces more precipitation. 
For the second part of the study, a $10 \mathrm{~km}$ horizontal resolution RegCM simulation (hereinafter referred to as RegCM4.3_BATS_10km) nested into the previously described RegCM4.3 BATS_50km simulation was performed over a Central European domain (Fig. 1, bottom) with identical parameterization settings (which in this case means $2 \mathrm{~km} \times 2 \mathrm{~km}$ surface tiles). RegCM was run with the mixed cumulus scheme, i.e., the MIT-Emanuel approximation (Emanuel, 1991; Emanuel and Zivkovic-Rothman, 1999) is used above sea surface and the Grell (1993) above land surface with the closure of Fritsch and Chappell (1980). The region-specific comparison of the results using the different parametrization schemes of convective processes and their detailed descriptions are presented in Pieczka et al. (2017).

\subsection{Validation data}

We use the E-OBS gridded daily database (Haylock et al., 2008) to validate the ability of the models to describe present climatic conditions. This database is a gridded time-series dataset covering the period $1950-2016$ for the area of $25^{\circ} \mathrm{N}-$ $75^{\circ} \mathrm{N}, \quad 40^{\circ} \mathrm{W}-75^{\circ} \mathrm{E}$ at $0.25^{\circ}$ horizontal resolution, and contains several meteorological variables. A detailed comparison of E-OBS to other regional datasets can be found in Prein and Gobiet (2017), who highlight the uneven geographical distribution of stations included in the interpolation of available data and the production of the gridded datasets. The lack of stations can generate further problems during validation, especially in precipitation-related variables, and in the eastern European countries, including Hungary.

For the validation of the RegCM4.3_BATS_10km, we decided to use the Carpatclim data, which is a high resolution homogeneous gridded database covering the period 1961-2010 for the Carpathian Region with $0.1^{\circ}$ horizontal resolution, and containing all the major surface meteorological variables (Szalai et al., 2013; Spinoni et al., 2015). Daily temperature (min, mean, max) and precipitation datasets were downloaded from the Carpatclim portal for the validation domain (i.e., $44^{\circ} \mathrm{N}-50^{\circ} \mathrm{N}, 17^{\circ} \mathrm{E}-27^{\circ} \mathrm{E}$ ) and compared to the simulated values. The density of stations used for the production of the gridded dataset is five-fold of that in the E-OBS (Prein and Gobiet, 2017).

The 1986-2005 time frame covers 20 years instead of 30 years, which is the standard length of climate normals. The use of 20-year-long periods can already be considered long enough to form a climatological sample (e.g., Arguez and Vose, 2011; Arguez et al., 2013). Moreover, 1986-2005 is used for the sake of consistency with the latest Assessment Report of the Intergovernmental Panel on Climate Change (e.g., Chapter 12 of IPCC, 2013). 


\section{Results and discussion}

Traditional tools for evaluating the models' ability to describe regional climatic conditions include the statistical analysis of (i) annual and seasonal mean fields and mean error fields relative to the reference measurements, and (ii) climate indices. Here, we focus on temperature and precipitation as being the two most often used climatic elements in determining the local conditions. First, validation for the mean temperature and precipitation is discussed, and then validation of some selected climate indices is presented.

\subsection{Validation of the mean values of temperature and precipitation}

The spatial distribution of modeled annual and seasonal mean temperature and precipitation data (Figs. 2 and 3, respectively) is similar to that of the observed data. However, locally some differences can be identified, e.g., in the temperature values of the Alps among different datasets in winter, and in Eastern Europe in summer, and there are differences in the seasonal precipitation values of the Alps and over Turkey among different datasets. More specifically, the detailed comparison of regional bias is summarized in Table 1, from which the following regions can be highlighted, where both the temperature and precipitation bias decreased overall from the HadGEM to the RegCM simulations: the southern part of the British Isles, North France, the North European Plain, the Carpathian Basin (except in summer). Nevertheless, in other regions (e.g., in the Iberian Peninsula) the bias increased substantially. The amplitude of the simulated annual temperature cycle is more intense, especially in the global model: summer temperature is overestimated, while winter temperature is underestimated over most of the entire domain (Fig. 4). The application of RegCM generally reduces negative bias in winter, and transforms the structure of the error pattern in summer: the southern part of Western Europe becomes colder, while Central and Eastern Europe becomes warmer than in the E-OBS. This behavior is not limited to summer, and can also be identified in the other seasons, but is less emphasized. 


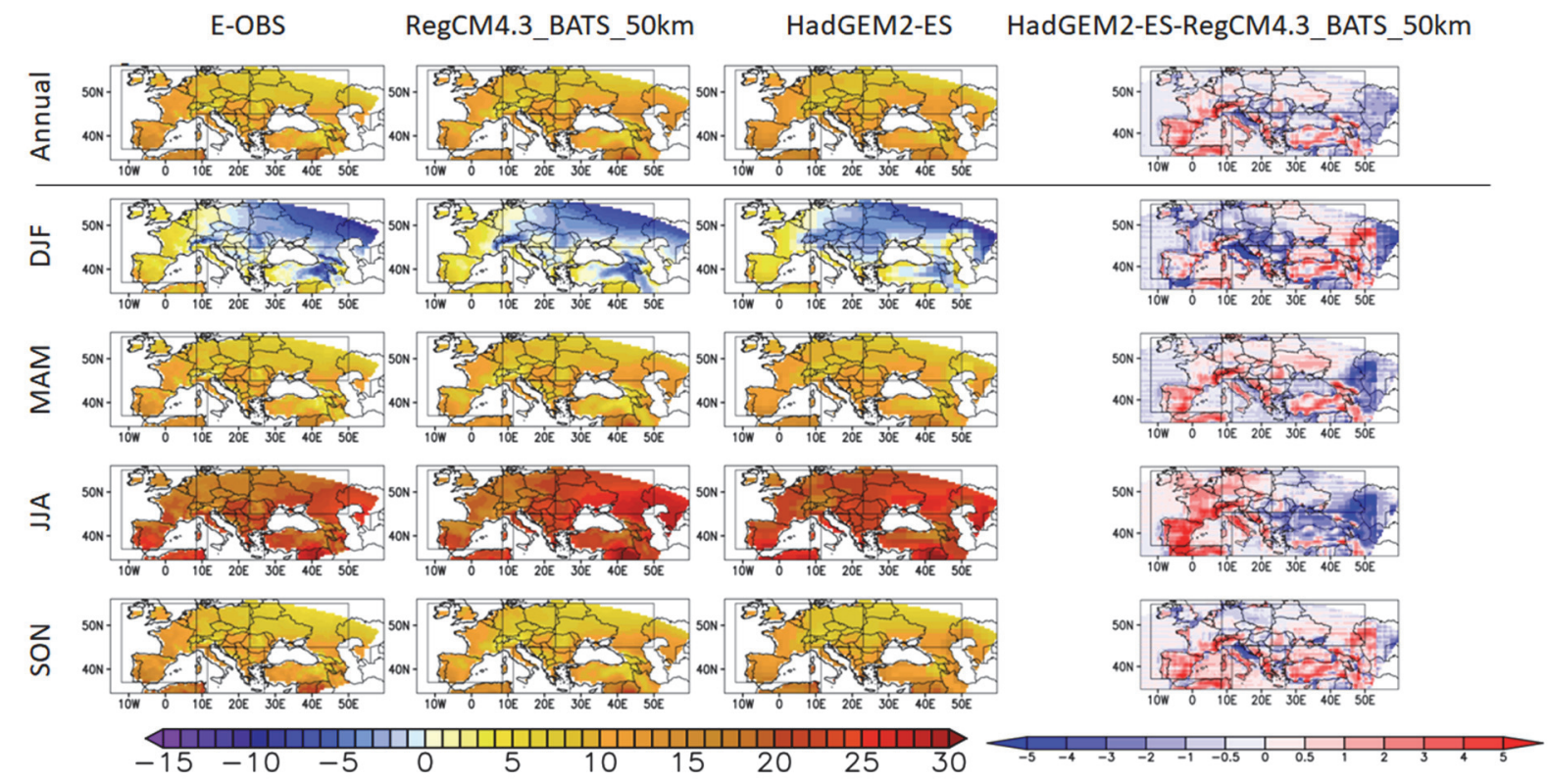

Fig. 2. Annual and seasonal mean temperature $\left({ }^{\circ} \mathrm{C}\right)$ of E-OBS (left), RegCM4.3_BATS_50km (2nd column), HadGEM2-ES (3rd column), and the difference of model simulations (right), for the period 1986-2005. For the sake of visual comparison, all fields are interpolated to the grid of RegCM4.3_BATS_50km.

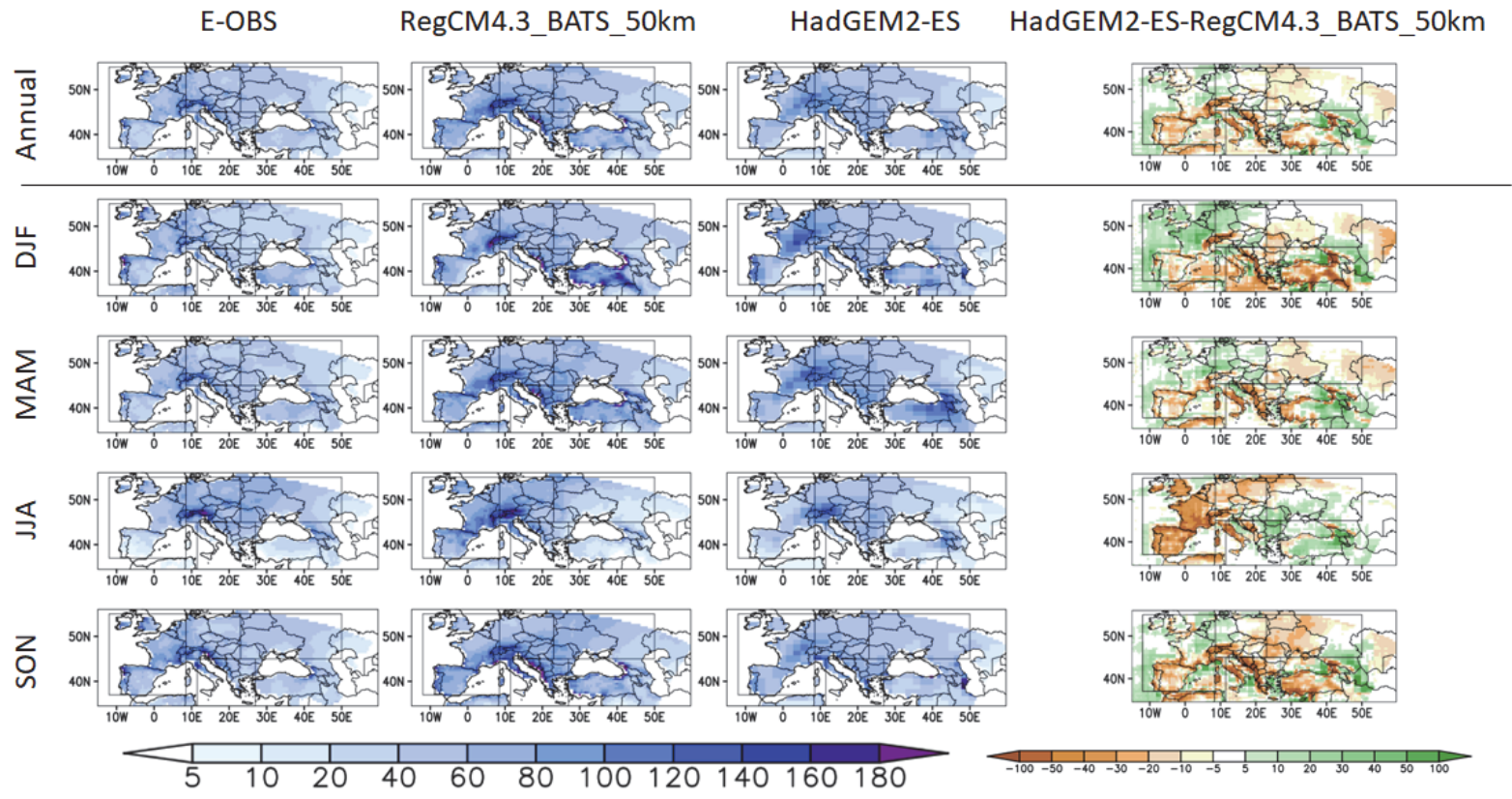

Fig. 3. Annual and seasonal mean precipitation ( $\mathrm{mm} / \mathrm{month}$ ) of E-OBS (left), RegCM4.3_BATS 50km (2nd column), HadGEM2-ES (3rd column), and the difference of model simulations (right), for the period 1986-2005. For the sake of visual comparison, all fields are interpolated to the grid of RegCM4.3_BATS_50km. 
Table 1. Visualization of the comparison of HadGEM2-ES/ RegCM4.3_BATS_50km model performance based on regional bias values relative to E-OBS reference data, for the period 1986-2005. Green: better performance of RCM, light brown: better performance of GCM, white: similar performance.

\begin{tabular}{|l|c|c|c|c|c|c|c|c|c|c|}
\hline & Annual & \multicolumn{2}{|c|}{ DJF } & \multicolumn{2}{|c|}{ MAM } & \multicolumn{2}{|c|}{ JJA } & \multicolumn{2}{|c|}{ SON } \\
\hline & T & p & T & p & T & p & T & p & T & p \\
\hline Southern part of the British Isles & & & & & & & & & & \\
\hline France & & & & & & & & & & \\
\hline Iberian Peninsula & & & & & & & & & & \\
\hline North European Plain (in Germany and Poland) & & & & & & & & & & \\
\hline Alps & & & & & & & & & & \\
\hline Carpathian Basin & & & & & & & & & & \\
\hline East European Plain in Ukraine & & & & & & & & & & \\
\hline East European Plain in Russia & & & & & & & & & & \\
\hline Apennine Peninsula & & & & & & & & & & \\
\hline Balkan Region & & & & & & & & & & \\
\hline Greece & & & & & & & & & & \\
\hline Asia Minor (Turkey) & & & & & & & & & & \\
\hline
\end{tabular}

In general, higher overestimated temperature can be found in $\mathrm{RegCM}$ outputs in the northeastern part of the Med-CORDEX domain, while underestimation occurs in the southwestern part, with the highest gradient between the two regions existing during summer. This shift of the mean temperature bias field is an important result of the dynamical downscaling, since the application of RCM cools the GCM outputs substantially, by about $1-4{ }^{\circ} \mathrm{C}$ in general (the greatest exception is in Eastern Europe in summer). This is a known behavior of the RegCM, as similar conclusions can be seen for a completely different region, namely southeastern Asia in Giorgi et al. (1999). The cooling effect of RegCM on the driving GCM outputs is probably related to the treatment of cloud radiative processes (Coppola et al., 2014). Clouds generally reflect some portion of incoming shortwave radiation, thus the transmitted part is reduced, which later warms the surface and the atmosphere. The emitted longwave radiation is trapped less efficiently by higher level clouds compared to lower level and thicker clouds, hence nearsurface warming is less intense. Overall, thick, low level clouds have a stronger impact on temperature than high level clouds. Since the moisture-, and thus cloud-related processes are the weakest part of climate models in terms of understanding the climate system, their radiation effects cause uncertainty in the final results. Moreover, we assume that proximity to the moisture source, i.e., large water bodies, also has an important effect. As a 
result, cooling is the most pronounced in southern Europe (which is illustrated by the red color in this area in the right column of Fig. 2). In case of some subregions (e.g., the Iberian Peninsula, throughout the year) the cooling effect becomes too strong, while in the eastern part (Carpathian Basin, East European Plain, Asia Minor) of the domain warm bias still remains in summer despite the present cooling effect. However, for instance, in the Carpathian Basin during winter this general cooling effect is not present at all, namely, the seasonal mean of $\mathrm{RegCM}$ outputs are $1-2{ }^{\circ} \mathrm{C}$ warmer than that of HadGEM2-ES outputs, which can be partly explained by the smaller interannual variability of mean winter temperature values using RegCM simulation compared to the HadGEM2-ES driving simulation.
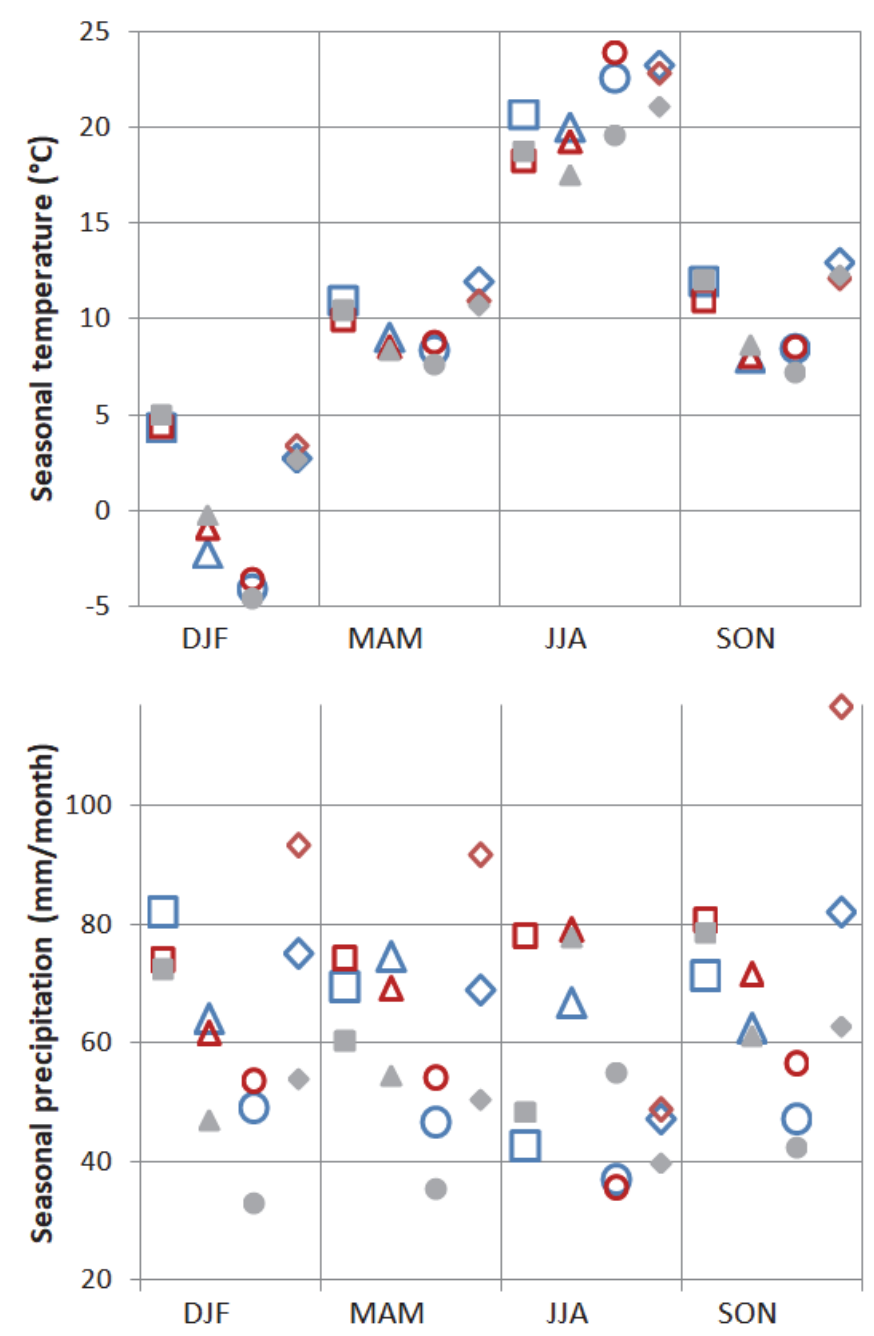

Fig. 4. Comparison of the simulated seasonal mean temperature (top) and precipitation (bottom) values over land to the E-OBS reference data for the four regions, for the period 1986-2005. (Colors and symbols are as follows: HadGEM2-ES: blue, RegCM4.3_BATS_50km: red, E-OBS: grey; Western Europe: square, Central Europe: triangle, Eastern Europe: circle; Southern Europe: diamond)

The temperature mean values of RegCM4.3 BATS $10 \mathrm{~km}$ closely follow those of RegCM4.3_BATS_50km, but show more local details, as expected. The 
differences between the simulations are greater in case of precipitation, which is the consequence of higher overall spatial variability compared to temperature. The spatial distribution of meteorological variables in the model generally reflects that of the observations, nevertheless, with excessive precipitation in the Carpathian Mountains, except in summer (Fig. 5).

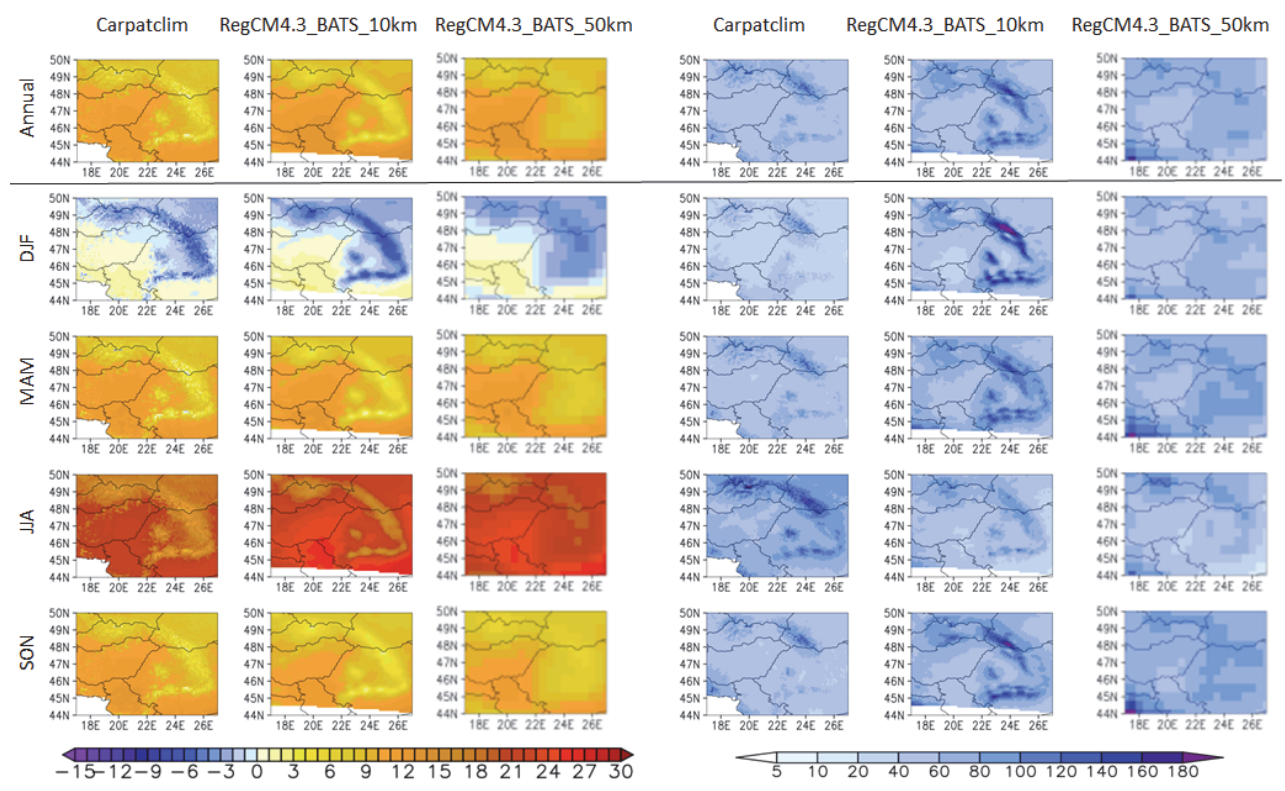

Fig. 5. Annual and seasonal mean temperature $\left({ }^{\circ} \mathrm{C}\right)$ and precipitation $(\mathrm{mm} / \mathrm{month})$ of Carpatclim (left), RegCM4.3_BATS_10km (center), and RegCM4.3_BATS_50km (right), for the period 1986-2005.

In most parts of the model domain, HadGEM2-ES outputs are wetter compared to E-OBS (Figs. 3 and 4), except in summer, when more than half of the region is drier in the model than the observations. The exceptions (e.g., the regions with more precipitation in summer) are located in the southern part of the domain. The areas of local precipitation maximum are slightly displaced in some seasons. The location and spatial distribution of precipitation are better represented in RegCM (e.g., the local maxima in the Alps or on the shores of the Adriatic Sea is noticeable in RegCM outputs, although sometimes they are too strong) than in HadGEM2-ES outputs, which is not surprising due to the refined orography and land-sea mask. RegCM often produces excessive precipitation compared to HadGEM2-ES, resulting in overestimation, except in summer in the eastern part of the domain. Furthermore, RegCM increases the precipitation in the mountains compared to HadGEM2-ES, probably due to local orographical forcings present in the finer resolution model. In some cases (when HadGEM2-ES provides a good estimation for the amount of precipitation) this effect is too strong and causes 
excessive precipitation, while in other locations it improves the modeled results. In the western part of the domain no real improvement can be seen.

\subsection{Validation of climate indices}

The use of regional models and their increasing resolution are believed to add value not necessarily to the means, but to higher order statistics, and to the tails of the distribution function. Therefore, we selected climate indices (Table 2) to study the exceedance of given thresholds, and duration of specific phenomena. To illustrate the model behavior, both temperature and precipitation related indices are represented, also, the left and right tails of the distribution curve are considered. Unlike the simpler annual distribution of temperature, which allows an annual analysis, precipitation requires more detailed, seasonal analysis (in this paper summer and winter are presented). For the analysis the deviation from E-OBS (and for RegCM4.3_BATS_10km from Carpatclim) was calculated, and areas with significant biases were located.

Table 2. Definition of selected climate indices

\begin{tabular}{ll}
\hline \hline Name & Definition \\
\hline \hline SU (Summer days) & number of days per time period when T2max $>25{ }^{\circ} \mathrm{C}$ \\
TR (Tropical nights) & number of days per time period when T2min $>20^{\circ} \mathrm{C}$ \\
FD (Frozen days) & number of days per time period when T2min $<0{ }^{\circ} \mathrm{C}$ \\
ID (Ice days) & number of days per time period when T2max $<0{ }^{\circ} \mathrm{C}$ \\
RX1day & highest one day precipitation amount (mm) \\
R10mm & number of days with daily precipitation sum exceeding $10 \mathrm{~mm}$ \\
DD (Dry days) & $\begin{array}{l}\text { number of dry days } \\
\text { (with daily precipitation amount below } 1 \mathrm{~mm} \text { ) }\end{array}$ \\
CDD (Consecutive dry days) & $\begin{array}{l}\text { maximum number of consecutive dry days } \\
\text { (with daily precipitation amount below } 1 \mathrm{~mm} \text { ) }\end{array}$ \\
\hline
\end{tabular}

The spatial structures of temperature index values are reproduced reasonably well by the models compared to the reference data (Figs. 6 and 7). The biases 
already present in the summer mean temperature can be seen in the bias maps of SU and TR, too. However, although the bias of mean temperature was significant almost everywhere, this is not the case with TR, where the area with significant bias is reduced to a much smaller region north of the Caucasus (Fig. 8). The spatial structure of SU bias correlates well with mean temperature bias, and the impact of RegCM4.3_BATS_50km is also similar: it shifts temperature distribution to the left, but this shift (i.e., cooling effect) is too intense in some areas, causing underestimation in Western Europe, for instance. The structure and intensity of SU in Eastern Europe is similar in RegCM4.3_BATS_50km and HadGEM2-ES.

SU

a)

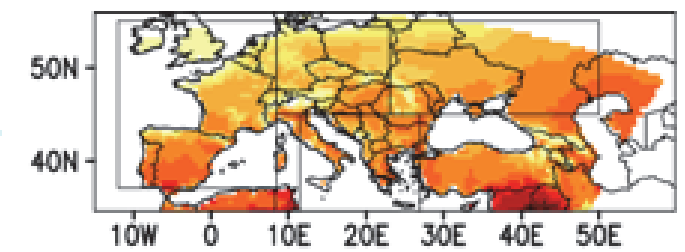

b)

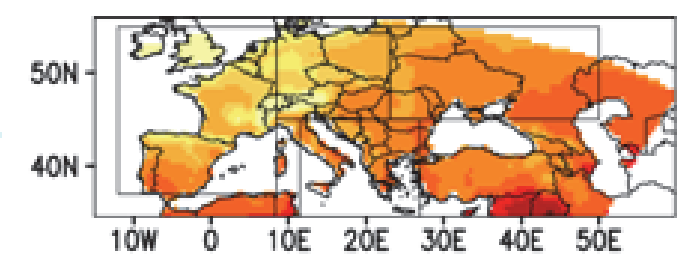

c)

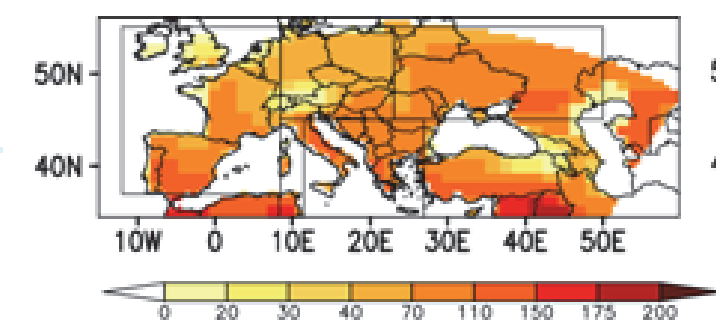

TR
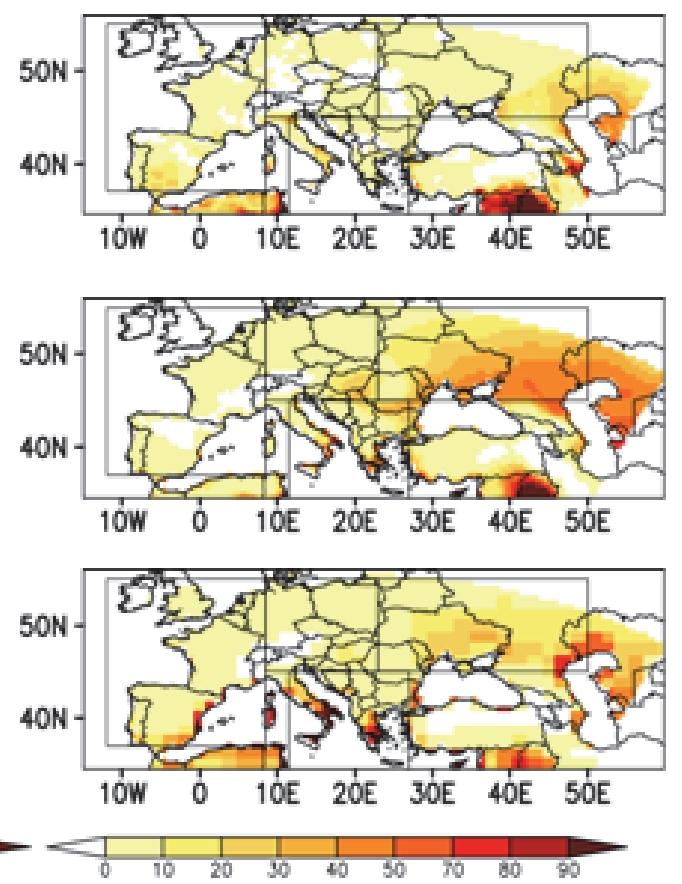

Fig. 6. Mean annual number of days of SU (left) and TR (right) in E-OBS (a, top), RegCM4.3_BATS_50km (b, middle), and HadGEM2-ES (c, bottom), for the period 1986-2005. For the sake of visual comparison, all fields are interpolated to the grid of RegCM4.3_BATS_50km. 
ID

a)
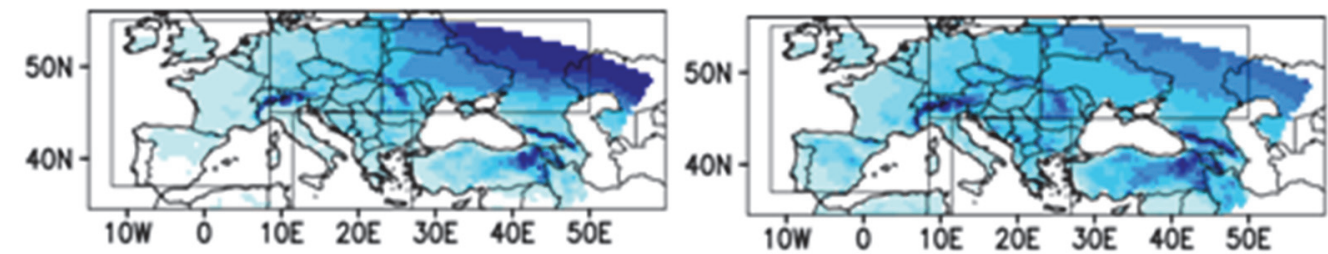

b)
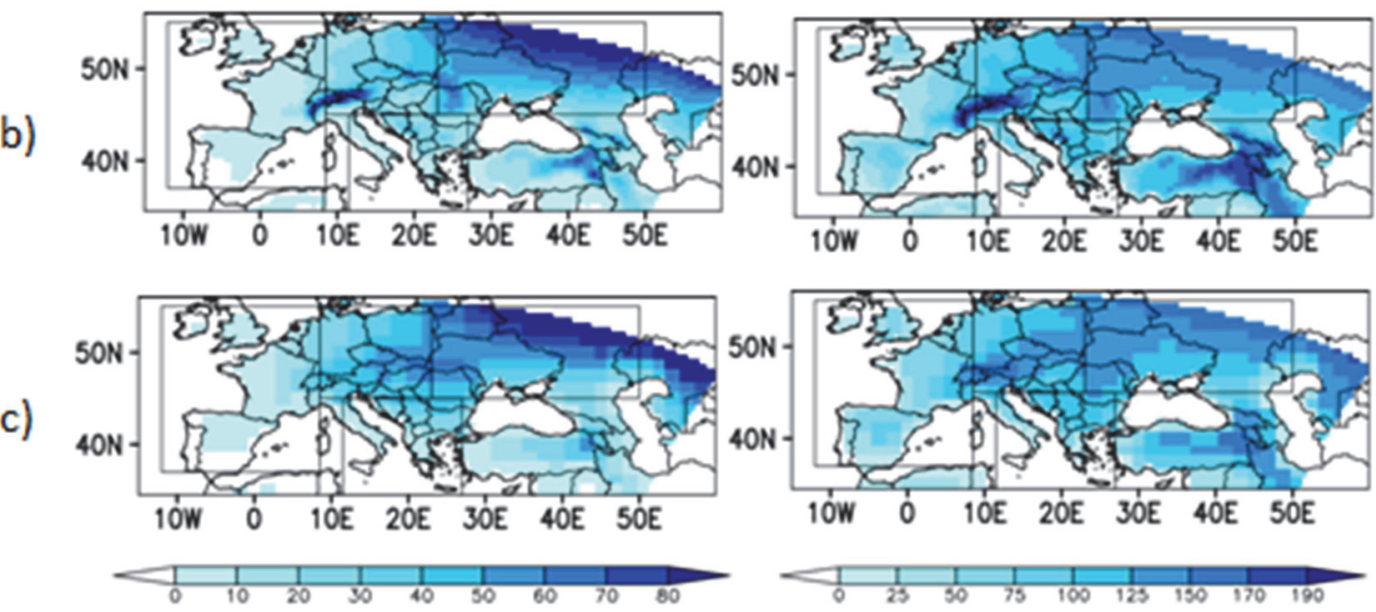

Fig. 7. Mean annual number of days of ID (left) and FD (right) in E-OBS (a, top), HadGEM2-ES (b, middle), and RegCM4.3 BATS 50km (c, bottom), for the period 1986-2005. For the sake of visual comparison, all fields are interpolated to the grid of RegCM4.3_BATS_50km.

SU

a)

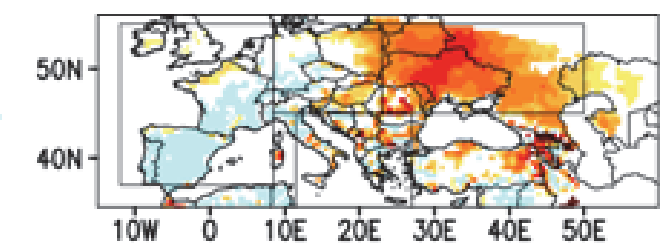

b)

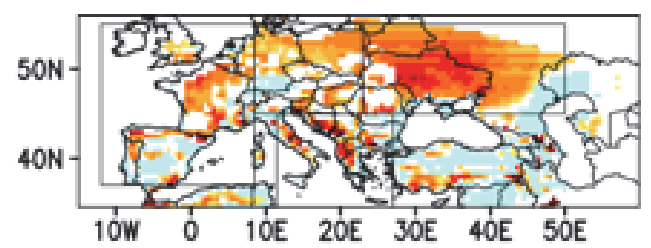

TR
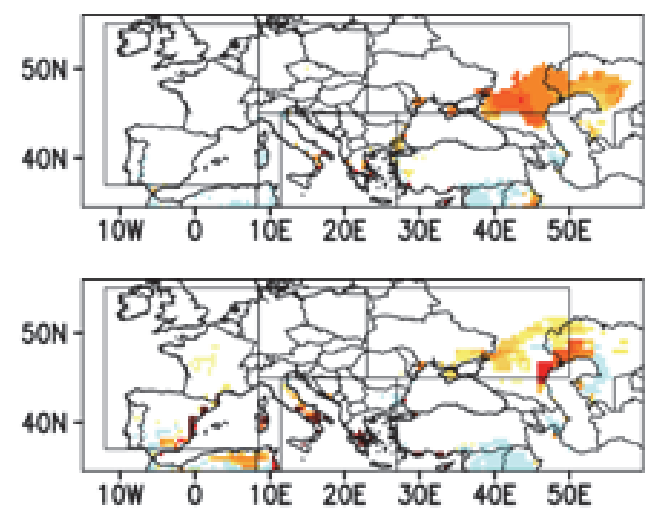

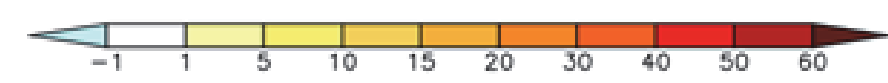

Fig. 8. Bias values (in days) of SU (left) and TR (right) in RegCM4.3_BATS_50km (a, top), and HadGEM2-ES (b, bottom), showing the significant values only, for the period 1986-2005 (reference data: E-OBS). For the sake of visual comparison, all fields are interpolated to the grid of RegCM4.3_BATS_50km. 
The spatial structure of the bias of ID and FD (Fig. 9) shows similarities to the winter mean temperature bias: colder, therefore overestimated ID and FD in most of the domain, while warmer, therefore underestimated ID and FD around the Caspian Sea. The models seem to be more successful in simulating the indices with lower values (i.e., ID, TR) than with higher values (i.e., FD, SU) if the bias is expressed in days, which is not surprising because of the less frequent occurrence, and thus, smaller potential differences between simulated and observed frequency values. This could also be evaluated using bias expressed as relative difference; however, in case of rare events, such a measure would misleadingly magnify small differences.

ID

a)

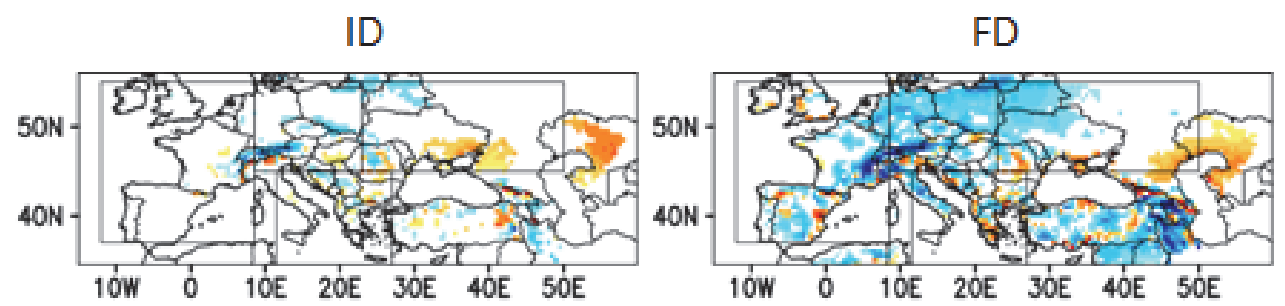

b)

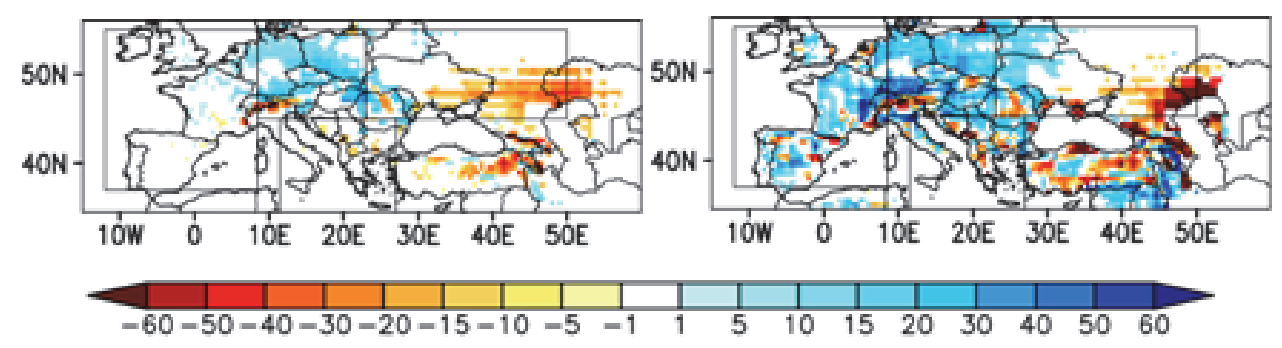

Fig. 9. Bias values (in days) of ID (left) and FD (right) in RegCM4.3_BATS_50km (a, top), and HadGEM2-ES (b, bottom), showing the significant values only, for the period 1986-2005 (reference data: E-OBS). For the sake of visual comparison, all fields are interpolated to the grid of RegCM4.3_BATS_50km.

Besides the bias maps, RMSE is another performance statistical parameter used for climate indices, e.g., Sillmann et al. (2013), Razavi et al. (2016). Since simple bias can hide differences between two spatial patterns because opposite differences can eliminate each other, RMSE adds more detail to the comparison due to its definition containing squared differences. Chai and Draxler (2014) suggest using both bias and RMSE to evaluate model performance. Table 3 summarizes the spatial average RMSE values for indices, regions, and models. In case of temperature indices, RegCM4.3_BATS_50km clearly performs better than HadGEM2-ES, except for TR in Central and Eastern Europe. For Hungary, 
RegCM4.3_BATS_10km results in similar magnitude RMSE values (compared to Carpatclim reference data), and a slight improvement can be seen between the RegCM runs with $10 \mathrm{~km}$ and $50 \mathrm{~km}$ at the left tail of the distribution (e.g., for FD and ID), whereas larger improvements appear between the RegCM and GCM results (for FD, ID, and SU). This is probably connected to the better representation of orography at the resolution used by RCM, which allows for a more realistic appearance of the barrier (or basin) effect, and which blocks cold air masses arriving from the north during winter.

Table 3. Spatial RMSE of climate indices calculated for the four regions and Hungary in case of RegCM4.3_BATS_10km (R10 - for Hungary only), RegCM4.3_BATS_50km (R50) and HadGEM2-ES (H) outputs (reference data: E-OBS for Europe and Carpatclim for Hungary). Calculations were performed on a $50-\mathrm{km}$ grid.

\begin{tabular}{l|rr|rr|rr|rr|rrr}
\hline \hline & \multicolumn{2}{|c|}{ Western } & \multicolumn{2}{|c|}{ Central } & \multicolumn{2}{c|}{ Eastern } & \multicolumn{2}{c}{ Southern } & \multicolumn{3}{|c}{ Hungary } \\
& R50 & \multicolumn{1}{c}{ H } & R50 & H & R50 & H & R50 & H & R10 & R50 & H \\
\hline \hline SU & 26.8 & 29.2 & 21.5 & 28.4 & 30.3 & 37.1 & 28.9 & 35.8 & 24.9 & 21.5 & 26.5 \\
TR & 5.6 & 8.8 & 7.9 & 5.7 & 22.2 & 14.0 & 25.9 & 27.7 & 26.2 & 22.3 & 13.2 \\
FD & 23.4 & 27.1 & 32.4 & 34.3 & 21.8 & 26.8 & 26.8 & 30.7 & 27.6 & 28.5 & 33.6 \\
ID & 5.6 & 7.9 & 20.7 & 28.8 & 21.6 & 27.6 & 10.5 & 16.6 & 17.2 & 17.2 & 36.3 \\
& & & & & & & & & & & \\
RX1day, winter & 14.5 & 13.8 & 10.1 & 9.8 & 8.6 & 6.9 & 18.9 & 13.3 & 9.7 & 8.7 & 11.0 \\
RX1day, summer & 19.0 & 12.8 & 19.0 & 15.8 & 14.7 & 13.6 & 18.6 & 13.2 & 17.7 & 17.8 & 17.9 \\
& & & & & & & & & & & \\
R10mm, winter & 5.2 & 5.9 & 3.2 & 3.2 & 2.7 & 2.0 & 6.1 & 5.0 & 2.4 & 2.3 & 2.5 \\
R10mm, summer & 5.7 & 3.6 & 5.4 & 4.9 & 3.6 & 4.0 & 4.5 & 3.6 & 5.2 & 5.0 & 5.2 \\
& & & & & & & & & & & \\
DD, winter & 13.6 & 13.8 & 14.7 & 15.8 & 10.9 & 13.6 & 16.7 & 14.5 & 10.3 & 12.8 & 20.6 \\
DD, summer & 15.6 & 12.4 & 12.4 & 13.6 & 13.0 & 10.8 & 12.2 & 14.4 & 11.6 & 11.4 & 15.7 \\
CDD, winter & 10.5 & 10.8 & 11.1 & 10.5 & 8.2 & 9.1 & 12.3 & 11.9 & 11.6 & 11.9 & 13.2 \\
CDD, summer & 15.0 & 14.7 & 9.0 & 7.5 & 17.6 & 11.1 & 18.8 & 15.9 & 12.9 & 12.6 & 8.5 \\
\hline
\end{tabular}

Precipitation in RegCM4.3_BATS_50km is too intense compared to both E-OBS and HadGEM2-ES: not only is the mean precipitation higher, but RX1day is also generally overestimated. This is a common behavior of regional models (Soares et al., 2012). The difference between the RMSE of the two simulations is more pronounced in Western and Central Europe in summer, 
when the contribution of local scale processes (e.g., convection) is stronger in the region than in winter. Interestingly, this seasonal difference cannot be seen in Eastern and Southern Europe. This is related, especially in Eastern Europe, to drier and warmer conditions present in the models compared to observation, probably limiting convection, and therefore reducing seasonality.

The spatial structure of $\mathrm{R} 10 \mathrm{~mm}$ is similar in the observed and modeled data, with better spatial representation of RegCM4.3_BATS_50km than HadGEM2-ES. RMSE values are smaller than for Rx1day, however, the absolute values of R10mm are also smaller. These deficiencies may partly originate from the reference database (Prein and Gobiet, 2017), e.g., precipitation undersampling in E-OBS. Results for the drought-related indices (DD, CDD) lead to less clear conclusions, and depend on region and season.

In the half of the examined indices, regions, and periods, the RMSE of RegCM4.3_BATS_50km was smaller than that of HadGEM2-ES. For Hungary this ratio is even better (10 seasonal indices out of the total 12 seasonal indices included in Table 3 show better performance of RegCM4.3_BATS_50km). Nevertheless, RMSE values from RegCM4.3_BATS_10km and RegCM4.3_BATS_50km are close to each other with small overall differences between the estimations using different resolutions.

To decide which model performs better is a complex task, because it includes several factors, e.g., it depends on the goal of the study. However, the magnitude and spatial extent of bias are usually among the most important components. Therefore, after calculating biases and their significance (using Welch's test), we prepared the histograms for all regions. In order to keep the paper to a reasonable length, only one example is shown here from the 90 histograms prepared during the analysis, see Fig. 10 as an illustration. Then, we introduced the measure $m$ as follows:

$$
m=\left|m_{-}\right|+\left|m_{+}\right|=\left|\sum_{i=1}^{N_{-}} f_{i} \cdot b_{i}\right|+\left|\sum_{i=1}^{N_{+}} f_{i} \cdot b_{i}\right|,
$$

where $f_{i}$ is relative frequency of bias $b_{i}$, and the corresponding products are summed for the underestimation (with $N_{-}$different bias categories) and overestimation (with $N_{+}$different bias categories).

Table 4 summarizes the results separately for underestimation and overestimation (on the basis of $m_{-}$and $m_{+}$, respectively) for comparing HadGEM2-ES with RegCM4.3_BATS_50km. A cell is colored green when the introduced metrics (either $m_{-}$and $m_{+}$) are better for RCM than GCM, and light brown if the opposite happens. White means that the performance of the two models using different resolutions is close to each other. 


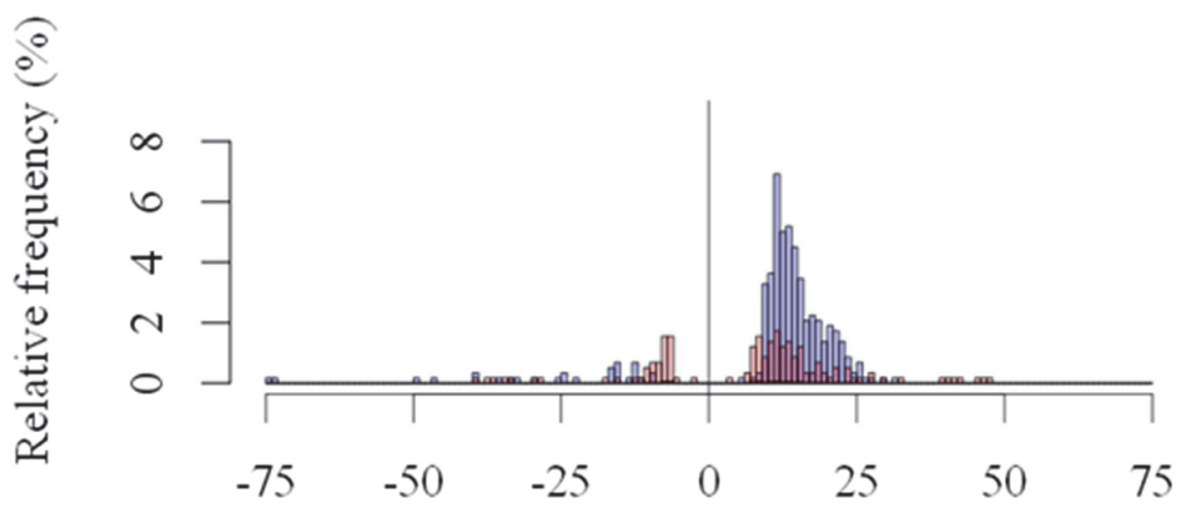

Fig. 10. Histogram of significant bias values of ID (days) in RegCM4.3_BATS_50km (red) and HadGEM2-ES (blue) for Central Europe, showing the significant values only, for the period 1986-2005 (reference data: E-OBS).

Table 4. Visualization of the comparison of HadGEM2-ES/RegCM4.3_BATS_50km model performance based on the metric defined in the text. Green: better performance of RCM, light brown: better performance of GCM, white: similar performance. U: underestimation (representing $m_{-}$, for definition see text), $\mathrm{O}$ : overestimation (representing $m_{+}$, for definition see text).

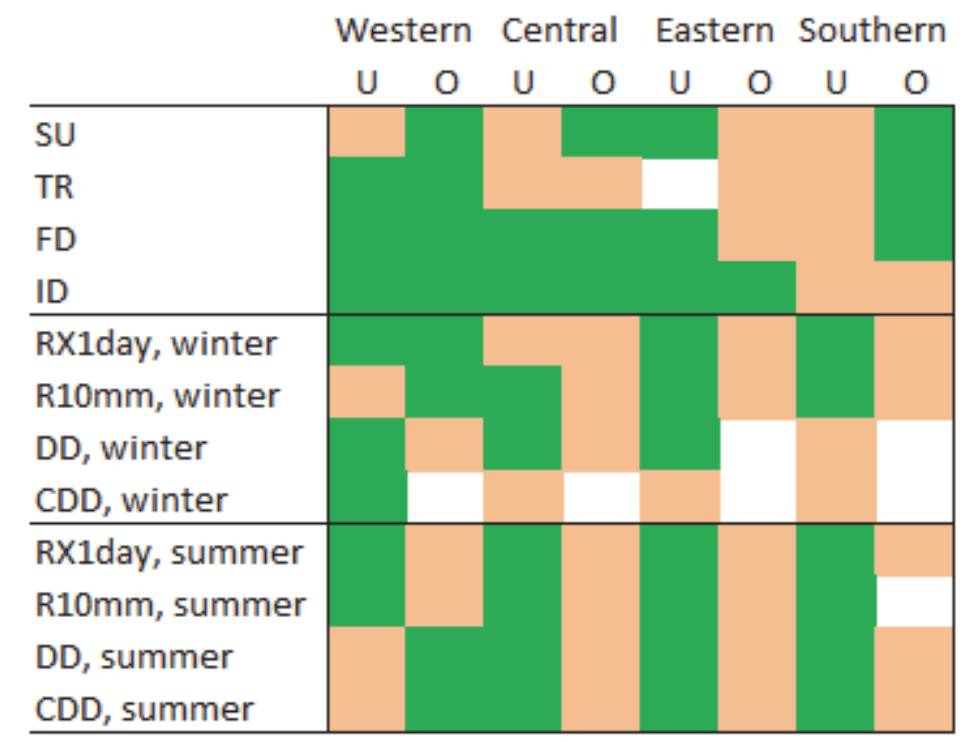

In case of temperature indices (the upper four lines of Table 4), a general improvement can be identified in Western Europe, and a clear improvement is seen in cold indices in Central Europe. The underestimation of temperature indices improved in Eastern Europe and their overestimation improved in Southern Europe. 
In case of precipitation indices (the middle and lower four lines of Table 4 for winter and summer, respectively) the influence of RegCM is usually too strong, and underestimation turns to overestimation and vice versa. For instance, the underestimation of the precipitation indices in summer improves (i.e., decreased) with finer resolution, however, the overall effect of overestimation increases in the regions representing Central, Eastern, and Southern Europe. A similar shift can be seen in the case of RX1day and R10mm in (i) Western Europe in summer, and in (ii) Eastern and Southern Europe in winter. Opposite changes (improved overestimation with increased underestimation) occur in the drought-related indices (i.e., DD and CDD) in Western Europe in summer. Among the precipitation-related indices, only RX1day shows clear improvement in terms of both overestimation and underestimation in Western Europe.

\section{Conclusions}

The novelty of the analysis stems from the unique set-up of RegCM applied to the Med-CORDEX and Carpathian regions. The CORDEX international initiative recommends completing several experiments using different regional climate models for the pre-defined 14 regions (Lake et al., 2017). This paper contributes to this international effort by evaluating our RegCM simulations. In addition, the main validation results of recent RegCM4 simulations are summarized in this paper in order to facilitate and inform the researchers and users of the RegCM4 simulation outputs during their planning and performance of climate change impact studies, which strongly rely on climatological input. On the basis of the presented results, the following conclusions can be drawn.

(1) The spatial distribution of the annual and seasonal mean temperature and precipitation is sufficiently simulated by the models with all the presented resolutions.

(i) The highest temperature biases occur in summer in Eastern Europe. The impact of the dynamical downscaling with RegCM is not uniform throughout the region and year: although it generally cools the HadGEM results, its magnitude depends on the distance from the ocean, and orography.

(ii) The location and spatial distribution of precipitation is better represented in RegCM simulations than in HadGEM2-ES outputs, however, dynamical downscaling with higher resolution often increases precipitation in the mountains, and also produces excessive precipitation. 
(iii) The temperature and precipitation mean values of RegCM4.3_BATS $10 \mathrm{~km}$ closely follow the mean values of RegCM4.3_BATS_50km.

(2) Regarding the climate indices:

(i) The overall spatial structure of temperature indices is reproduced reasonably well by the models, however, the consequence of the general biases in the mean temperature can be observed in the overestimation or underestimation of the index values in certain regions. In general, the models are more successful in simulating the indices with less frequent occurrence. A clear improvement can be recognized in the RMSE of temperature indices when using finer resolution.

(ii) In case of precipitation indices, the detected deficiencies partly originate from the reference database (especially in mountainous regions: even though the reference databases are carefully created, the number of measurement sites used is not sufficient in the areas with complex topography).

(3) A complex measure was introduced, which is able to take into account both the magnitude and spatial extent of bias.

(i) A general improvement can be recognized in all temperature-related climate indices in Central Europe and Western Europe, respectively. Furthermore, the underestimation (overestimation) of temperature indices improved in Eastern Europe (Southern Europe).

(ii) The influence of downscaling using finer resolution is usually too strong in the precipitation indices, which often changes underestimation into overestimation and vice versa.

\footnotetext{
Acknowledgements: Research leading to this paper was supported by the following sources: the Hungarian National Research, Development and Innovation Fund under grants K-120605 and K129162, the AGRÁRKLIMA2 project (VKSZ_12-1-2013-0034), the European Regional Development Fund and the Hungarian Government (GINOP-2.3.2-15-2016-00028), and the EEA Grant HU04 Adaptation to Climate Change Programme (EEA-C13-10). We acknowledge the E-OBS dataset from the EU-FP6 project ENSEMBLES (http://ensembles-eu.metoffice.com) and the data providers in the ECA\&D project (http://www.ecad.eu). The CARPATCLIM Database used in this study was compiled with the support of the European Commission in JRC in 2013.
} 


\section{References}

Anders, I. and Rockel, B., 2009: The influence of prescribed soil type distribution on the representation of present climate in a regional climate model. Clim. Dynam. 33, 177-186.

https://doi.org/10.1007/s00382-008-0470-y

Arguez, A. and Vose, R.S., 2011: The definition of the standard WMO climate normal: The key to deriving alternative climate normals. Bull. Amer.Meteorol. Soc. 92, 699-704.

https://doi.org/10.1175/2010BAMS2955.1

Arguez, A., Vose, R.S., and Dissen, J., 2013: Alternative climate normals: Impacts to the energy industry. Bull. Amer.Meteorol. Soc. 94, 915-917.

https://doi.org/10.1175/BAMS-D-12-00155.1

Bresson, R. and Laprise, R., 2011: Scale-decomposed atmospheric water budget over North America as simulated by the Canadian Regional Climate Model for current and future climates. Clim. Dynam. 36, 365-384. https://doi.org/10.1007/s00382-009-0695-4

Cavicchia, L. and von Storch, H., 2011: The simulation of medicanes in a high-resolution regional climate model. Clim. Dynam. 39, 2273-2290. https://doi.org/10.1007/s00382-011-1220-0

Chai, T. and Draxler, R.R., 2014: Root mean square error (RMSE) or mean absolute error (MAE)?Arguments against avoiding RMSE in the literature. Geosci. Model Dev. 7, 1247-1250. https://doi.org/10.5194/gmd-7-1247-2014

Collins, W.J., Bellouin, N., Doutriaux-Boucher, M., Gedney, N., Halloran, P., Hinton, T., Hughes, J., Jones, C.D., Joshi, M., Liddicoat, S., Martin, G., O'Connor, F., Rae, J., Senior, C., Sitch, S., Totterdell, I., Wiltshire, A., and Woodward, S., 2011: Development and evaluation of an Earthsystem model - HadGEM2. Geosci. Model Dev. Discuss. 4, 997-1062. https://doi.org/10.5194/gmdd-4-997-2011

Coppola, E., Giorgi, F., Raffaele, F., Fuentes-Franco, R., Giuliani, G., Llopart-Pereira, M., Mamgain, A., Mariotti, L., Diro, G.T., and Torma, Cs., 2014: Present and future climatologies in the phase I CREMA experiment. Climatic Change 125, 23-38. https://doi.org/10.1007/s10584-014-1137-9

Di Luca, A., de Elía, R., and Laprise, R., 2015: Challenges in the quest for added value of regional climate dynamical downscaling. Curr. Climate Change Rep. 1, 10-21. https://doi.org/10.1007/s40641-015-0003-9

Dickinson, R.E., Henderson-Sellers, A., and Kennedy, P.J., 1993: Biosphere-atmosphere Transfer Scheme (BATS) Version 1e as Coupled to the NCAR Community Climate Model. NCAR Technical Note NCAR/TN-387+STR. DOI: 10.5065/D67W6959

Donat, M., Leckebusch, G., Wild, S., and Ulbrich, U., 2010: Benefits and limitations of regional multimodel ensembles for storm loss estimations. Clim. Res. 44, 211-225. https://doi.org/10.3354/cr00891

Elguindi, N., Bi, X., Giorgi, F., Nagarajan, B., Pal, J., Solmon, F., Rauscher, S., Zakey, A., and Giuliani, G., 2011: Regional climatic model RegCM user manual version 4.3. ITCP, Trieste, Italy.

Elguindi, N., Giorgi, F., and Turuncoglu, U., 2014: Assessment of CMIP5 global model simulations over the subset of CORDEX domains used in the Phase I CREMA. Climatic Change 125, 7-21. https://doi.org/10.1007/s10584-013-0935-9

Emanuel, K.A., 1991: A scheme for representing cumulus convection in large-scale models. J Atmos Sci 48, 2313-2335.

https://doi.org/10.1175/1520-0469(1991)048<2313:ASFRCC $>2.0 . C O ; 2$

Emanuel, K.A. and Zivkovic-Rothman, M., 1999: Development and evaluation of a convection scheme for use in climate models. $J$ Atmos Sci 56, 1766-1782.

https://doi.org/10.1175/1520-0469(1999)056<1766:DAEOAC >2.0.CO;2 
Feser, F., 2006: Enhanced detectability of added value in limited-area model results separated into different spatial scales. Mon. Weather Rev. 134, 2180-2190. https://doi.org/10.1175/MWR3183.1

Flaounas, E., Drobinski, P., and Bastin, S., 2013: Dynamical downscaling of IPSL-CM5 CMIP5 historical simulations over the Mediterranean: benefits on the representation of regional surface winds and cyclogenesis. Clim. Dynam. 40, 2497-2513. https://doi.org/10.1007/s00382-012-1606-7

Fritsch, J.M. and Chappell, C.F., 1980: Numerical prediction of convectively driven mesoscale pressure systems. Part I: Convective parameterization. J. Atmos. Sci. 37, 722-1733. https://doi.org/10.1175/1520-0469(1980)037<1722:NPOCDM >2.0.CO;2

Gao, X., Shi, Y., Zhang, D., Wu, J., Giorgi, F., Ji, Z., and Wang, Y., 2012: Uncertainties in monsoon precipitation projections over China: Results from two high-resolution RCM simulations. Clim. Res. 52, 213-226. https://doi.org/10.3354/cr01084

Giorgi, F., 1990: Simulation of regional climate using a limited area model nested in a general circulation model. J. Climate 3, 941-63. https://doi.org/10.1175/1520-0442(1990)003<0941:SORCUA $>2.0 . C O ; 2$

Giorgi, F., Huang, Y., Nishizawa, K., and Fu, C., 1999: A seasonal cycle simulation over eastern Asia and its sensitivity to radiative transfer and surface processes. J. Geophys. Res. 104, 6403-6423. https://doi.org/10.1029/1998JD200052

Giorgi, F., Francisco, R., and Pal, J., 2003: Effects of a subgrid-scale topography and land use scheme on the simulation of surface climate and hydrology. Part I: Effects of temperature and water vapor disaggregation. J. Hydrometeorol. 4, 317-333. https://doi.org/10.1175/1525-7541(2003)4<317:EOASTA >2.0.CO;2

Giorgi, F., Coppola, E., Solmon, F., Mariotti, L., Sylla, M.B., Bi, X., Elguindi, N., Diro, G.T., Nair, V., Giuliani, G., Turuncoglu, U.U., Cozzini, S., Güttler, I., O'Brien, T.A., Tawfik, A.B., Shalaby, A., Zakey, A.S., Steiner, A.L., Stordal, F., Sloan, L.C., and Brankovic, C., 2012: RegCM4: model description and preliminary tests over multiple CORDEX domains. Climate Res. 2, 7-29. https://doi.org/10.3354/cr01018

Grell, G.A., 1993: Prognostic evaluation of assumptions used by cumulus parameterizations. Mon. Weather Rev. 121, 764-787. https://doi.org/10.1175/1520-0493(1993)121<0764:PEOAUB >2.0.CO;2

Grose, M., Pook, M., McIntosh, P., Risbey, J., and Bindoff, N., 2012: The simulation of cutoff lows in a regional climate model: Reliability and future trends. Clim. Dynam. 39, 445-459. https://doi.org/10.1007/s00382-012-1368-2

Haylock, M.R., Hofstra, N., Klein Tank, A.M.G., Klok, E.J., Jones, P.D., and New, M., 2008: A European daily high-resolution gridded dataset of surface temperature and precipitation. $J$. Geophys. Res (Atmospheres) 113, D20119. https://doi.org/10.1029/2008JD010201

IPCC, 2013: Climate Change 2013: The Physical Science Basis. Contribution of Working Group I to the Fifth Assessment Report of the Intergovernmental Panel on Climate Change (Eds. Stocker, T.F., Qin, D., Plattner, G.-K., Tignor, M., Allen, S.K., Boschung, J., Nauels, A., Xia, Y., Bex, V., Midgley, P.M.). Cambridge University Press, Cambridge, United Kingdom and New York, NY, USA.

Joetzjer, E., Douville, H., Delire, C., and Ciais, P., 2013: Present-day and future Amazonian precipitation in global climate models: CMIP5 versus CMIP3. Clim. Dynam. 41, 2921-2936. https://doi.org/10.1007/s00382-012-1644-1

Jones, C., Hughes, J.K., Bellouin, N., Hardiman, S.C., Jones, G.S., Knight, J., Liddicoat, S., O'Connor, F.M., Andres, R.J., Bell, C., and Boo, K.O., 2011: The HadGEM2-ES implementation of CMIP5 centennial simulations. Geosci. Mod.Develop. 4, 543. https://doi.org/10.5194/gmdd-4-689-2011

Kanamaru, H. and Kanamitsu, M., 2007: Fifty-seven-year California reanalysis downscaling at $10 \mathrm{~km}$ (CaRD10). Part II: Comparison with North American regional reanalysis. J. Climat. 20, 55725592. https://doi.org/10.1175/2007JCLI1522.1

Kawazoe, S. and Gutowski, W., 2013: Regional, very heavy daily precipitation in NARCCAP simulations. J. Hydrometeorol. 14, 1212-1227. https://doi.org/10.1175/JHM-D-12-068.1 
Kis, A., Pongrácz, R., Bartholy, J., and Szabó, J.A., 2017: The application of RCM results to hydrological analysis. Idójárás 121, 437-452.

Knutti, R., Masson, D., and Gettelman, A., 2013: Climate model genealogy: Generation CMIP5 and how we got there. Geophys. Res. Lett. 40, 1194-1199. https://doi.org/10.1002/grl.50256

Krüzselyi, I., Bartholy, J., Horányi, A., Pieczka, I., Pongrácz, R., Szabó, P., Szépszó, G., and Torma, Cs., 2011: The future climate characteristics of the Carpathian Basin based on a regional climate model mini-ensemble. Adv. Sci. Res. 6, 69-73. https://doi.org/10.5194/asr-6-69-2011

Lake, I., Gutowski, W., Giorgi, F., and Lee, B., 2017: CORDEX: Climate Research and Information for Regions. Bull. Amer. Meteorol. Soc. 98, ES189-ES192. https://doi.org/10.1175/BAMS-D-17-0042.1

Lucas-Picher, P., Wulff-Nielsen, M., Christensen, J., Adalgeirsdottir, G., Mottram, R., and Simonsen, $S$., 2012: Very high resolution regional climate model simulations over Greenland: Identifying added value. J. Geophys. Res. Atmos. 117, D02108. https://doi.org/10.1029/2011JD016267

Maraun, D., Widmann, M., Gutiérrez, J.M., Kotlarski, S., Chandler, R.E., Hertig, E., Wibig, J., Huth, R., and Wilcke, R.A.I., 2015: VALUE: A framework to validate downscaling approaches for climate change studies. Earth's Future 3, 1-14. https://doi.org/10.1002/2014EF000259

Pieczka, I., Pongrácz, R., Szabóné André, K., Kelemen, F.D., and Bartholy, J., 2017: Sensitivity analysis of different parameterization schemes using RegCM4.3 for the Carpathian region. Theor. App. Climatol. 130, 1175-1188. https://doi.org/10.1007/s00704-016-1941-4

Prein, A.F. and Gobiet, A., 2017: Impacts of uncertainties in European gridded precipitation observations on regional climate analysis. Int. J. Climatol. 37, 305-327. https://doi.org/10.1002/joc.4706

Rauscher, S.A., Coppola, E., Piani, C., and Giorgi, F., 2010: Resolution effects on regional climate model simulations of seasonal precipitation over Europe. Clim. Dynam. 35, 685-711. https://doi.org/10.1007/s00382-009-0607-7

Razavi, T., Switzman, H., Arain, A., Coulibaly, P., 2016: Regional climate change trends and uncertainty analysis using extreme indices: A case study of Hamilton, Canada. Climate Risk Manage. 13, 43-63. https://doi.org/10.1016/j.crm.2016.06.002

Sillmann, J., Kharin, V.V., Zhang, X., Zwiers, F.W., and Bronaugh, D., 2013: Climate extremes indices in the CMIP5 multimodel ensemble: Part 1. Model evaluation in the present climate. J.Geophys. Res.: Atmospheres 118, 1716-1733.

https://doi.org/10.1002/jgrd.50203

Soares, P.M.M., Cardoso, R.M., Miranda, P.M.A., Viterbo, P., and Belo-Pereira, M., 2012: Assessment of the ENSEMBLES regional climate models in the representation of precipitation variability and extremes over Portugal. J. Geophys. Res. 117, D07114.

https://doi.org/10.1029/2011JD016768

Somot, S., et al., 2012: The Med-CORDEX initiative: towards fully coupled Regional Climate System Models to study the Mediterranean climate variability, change and impact. Geophys. Res. Abst. 14,6080 .

Spinoni, J., Szalai, S., Szentimrey, T., Lakatos, M., Bihari, Z., Nagy, A., Németh, Á., Kovács, T., Mihic, D., Dacic, M., and Petrovic, P., 2015: Climate of the Carpathian Region in the period 19612010: climatologies and trends of 10 variables. Int. J. Climatol. 35, 1322-1341. https://doi.org/10.1002/joc.4059

Szalai, S., Auer, I., Hiebl, J., Milkovich, J., Radim, T., Stepanek, P., Zahradnicek, P., Bihari, Z., Lakatos, M., Szentimrey, T., Limanowka, D., Kilar, P., Cheval, S., Deak, Gy., Mihic, D., Antolovic, I., Mihajlovic, V., Nejedlik, P., Stastny, P., Mikulova, K., Nabyvanets, I., Skyryk, O., Krakovskaya, S., Vogt, J., Antofie, T., and Spinoni, J., 2013: Climate of the Greater Carpathian Region. Final Technical Report. http://www.carpatclim-eu.org 
Torma, C., Giorgi, F., and Coppola, E., 2015: Added value of regional climate modeling over areas characterized by complex terrain-Precipitation over the Alps. J.Geophys. Res.: Atmospheres 120, 3957-3972. https://doi.org/10.1002/2014JD022781

Vautard, R., Gobiet, A., Jacob, D., Belda, M., Colette, A., Déqué, M., Fernández, J., García-Diez, M., Goergen, K., Güttler, I., and Halenka, T., 2013: The simulation of European heat waves from an ensemble of regional climate models within the EURO-CORDEX project. Clim. Dynam. 41, 2555-2575. https://doi.org/10.1007/s00382-013-1714-z

Veljovic, K., Rajkovic, B., Fennessy, M.J., Altshuler, E.L., and Mesinger, F., 2010: Regional climate modeling: Should one attempt improving on the large scales? Lateral boundary condition scheme: Any impact? Meteorol. Z. 19, 237-246. https://doi.org/10.1127/0941-2948/2010/0460

Winterfeldt, $J$. and Weisse, R., 2009: Assessment of value added for surface marine wind speed obtained from two regional climate models. Mon. Weather Rev. 137, 2955-2965. https://doi.org/10.1175/2009MWR2704.1

Winterfeldt, J., Geyer, B., and Weisse, R., 2011: Using QuikSCAT in the added value assessment of dynamically downscaled wind speed. Int. J. Climatol. 31, 1028-1039.

Zahn, M. and von Storch, H., 2008: A long-term climatology of North Atlantic polar lows. Geophys. Res. Lett. 35, L22702. https://doi.org/10.1029/2008GL035769 